\title{
Median effective concentration of remifentanil for the inhibition of laryngoscope-induced cardiovascular responses
}

\author{
ZHENHAI LIU, FEI WANG, WEIZHI WANG and YANHUA LUO \\ Department of Anesthesiology, Weifang People's Hospital, Weifang, Shandong 261041, P.R. China
}

Received January 11, 2015; Accepted March 3, 2016

DOI: $10.3892 /$ etm.2016.3264

\begin{abstract}
The aim of this study was to calculate the median effective concentration $\left(\mathrm{EC}_{50}\right)$ of remifentanil (Rem) for the inhibition of laryngoscope-induced cardiovascular responses, and to observe its effects on the cardiovascular system and stress system. The study included 20 patients, who underwent time-scheduled vocal cord polyp resection with monitoring of heart rate (HR), mean blood pressure (MBP) and auditory evoked potential (AEP)-based A-line ARX Index (AAI). The Rem concentration was initially $5 \mathrm{ng} / \mathrm{ml}$ in the first patient, and the concentration selected for each subsequent patient was calculated from the previous case on the basis of whether or not cardiovascular reactions occurred. The HR, MBP and AAI at baseline, after the induction of anesthesia, and before and after the insertion of a self-retaining laryngoscope were recorded, with a change $>15 \%$ recorded as a positive cardiovascular response. The $\mathrm{EC}_{50}$ sequential method was used to calculate the $\mathrm{EC}_{50}$ of Rem for the inhibition of laryngoscope-induced responses. Cortisol, interleukin- 6 and blood glucose levels before and after laryngoscope insertion were also measured. The target-controlled concentrations for the 20 patients were as follows: 2 cases at $5 \mathrm{ng} / \mathrm{ml}, 6$ cases at $4.2 \mathrm{ng} / \mathrm{ml}, 6$ cases at $3.5 \mathrm{ng} / \mathrm{ml}, 4$ cases at $2.9 \mathrm{ng} / \mathrm{ml}$ and 2 cases at $2.4 \mathrm{ng} / \mathrm{ml}$. The $\mathrm{EC}_{50}$ of Rem for the inhibition of laryngoscope-induced responses was $3.5 \mathrm{ng} / \mathrm{ml}$ with a $95 \%$ confidence interval $(\mathrm{CI})$ of 3.47-3.60 ng/ml. A reasonable dose for inhibiting laryngoscope-induced responses was within the range $2.9-4.2 \mathrm{ng} / \mathrm{ml}$. In conclusion, Rem exhibited an $\mathrm{EC}_{50}$ of $3.5 \mathrm{ng} / \mathrm{ml}$ for the inhibition of laryngoscope-induced cardiovascular responses, with a $95 \%$ CI of 3.47-3.60 ng/ml, and a reasonable dose for the inhibition of such responses was $2.9-4.2 \mathrm{ng} / \mathrm{ml}$.
\end{abstract}

Correspondence to: Professor Yanhua Luo, Department of Anesthesiology, Weifang People's Hospital, 151 Guangwen Street Kuiwei, Weifang, Shandong 261041, P.R. China

E-mail: weizhiwangcn@126.com

Key words: remifentanil, target-controlled infusion, self-retaining laryngoscope, cardiovascular responses

\section{Introduction}

Surgery is currently the most commonly used treatment method for vocal cord polyps; however, the self-retaining laryngoscope used during surgery can cause severe cardiovascular reactions and stress responses, resulting in a series of changes in the nervous, endocrine and metabolic systems (1). This surgical procedure is delicate, with a high requirement for anesthesia; during the surgery, the vocal cord is required to remain stationary, as this should reduce the stress response and throat reflex, and fully relax the muscles, and also enable recovery and rehabilitation from the surgery as quickly as possible to avoid the aspiration of blood and oropharyngeal secretions (2). Therefore, it is vitally important to establish a scientifically confirmed and reasonable amount of anesthetic for use during the surgery.

A combination of the ultra-short-action opioid remifentanil (Rem) and ultra-short-action intravenous anesthetic propofol (Pro) is currently considered the best combination for total intravenous anesthesia (TIVA) (3). Rem has very short half-life, and so the continuous intravenous administration of Rem should not produce cumulative effects (4). In particular, its infusion time-related half-life is only 3-5 min; it is not notably decomposed by plasma cholinesterase; repeated or high-dose application does not affect the recovery time for spontaneous breathing and extubation after its discontinuation; and it can inhibit the decomposition of norepinephrine and corticosteroids (5). Pro is rapidly effective, with a short duration of action and rapid recovery, and it makes sedation easy to control (6-8). These two drugs are suitable for target-controlled infusion (TCI) in a short surgical procedure.

However, at present there have been no definitive studies concerning the dosage of Rem for use in surgery involving a self-retaining laryngoscope. Thus, the aim of the present study was to use the median effective concentration $\left(\mathrm{EC}_{50}\right)$ sequential test method to calculate the $\mathrm{EC}_{50}$ and $95 \%$ confidence interval (95\% CI) of the Rem-Pro combination for the inhibition of self-retaining laryngoscope-caused cardiovascular responses (SRLCCRs). Through observing changes of heart rate, mean arterial pressure, auditory evoked potential (AEP) index, cortisol, interleukin (IL)-6 and blood glucose prior to and following the induction of anesthesia, as well as prior to and following the self-retaining laryngoscope insertion, this study aimed to observe the inhibitory effects of Rem towards 
the cardiovascular system and SRLCCRs, aiming to provide a reference for its clinical use.

\section{Materials and methods}

General information. A total of 20 patients, who were subjected to vocal cord polyp resection under general anesthesia in Weifang People's Hospital (Weifang, China) from June 2009 to December 2012, were randomly selected for inclusion in the present study. The exclusion criteria were as follows: Circulation, glucose metabolism and nervous system dysfunctions; preoperative history of long-term application of analgesic or sedative drugs, with medication history that would interfere with glucose metabolism, adrenal function or the sympathetic system, with long-term history of alcohol abuse, long-term application of opioids or allergic response to opioids; endotracheal intubation could not be completed within $1 \mathrm{~min}$; serious cardiovascular reactions occurring during endotracheal intubation and laryngoscope insertion that prevented the surgery from proceeding. This study was approved by the ethics committee of Weifang People's Hospital. Written informed consent was obtained from the patients.

Anesthesia. All study subjects were set up for intravenous access after entry into the surgery room, and connected to a PM-6000 multi-parameter monitor (Mindray Bio-Medical Electronics Co., Shenzhen, China) to show electrocardiogram (ECG), heart rate (HR), pulse oxygen saturation $\left(\mathrm{SpO}_{2}\right)$, non-invasive arterial pressure $(\mathrm{BP})$ and Alaris AEP Index (AAI) values. Rem (batch no. 070904; Yichang Humanwell Pharmaceutical Co., Ltd., Yichang, China) and Pro (batch ET763; AstraZeneca SpA, Basiglio, Italy) were infused through a TCI-I type infusion pump (Slgo Medical Technology Co., Ltd., Beijing, China) for TCI. Rem was infused with the plasma target-controlled concentration in accordance with the $\mathrm{EC}_{50}$ sequential method; when the plasma concentration and effect-site concentration were in equilibrium [the half-life for equilibration $\left(\mathrm{T}_{1 / 2} \mathrm{Keo}\right)$ of Rem was $1.32 \mathrm{~min}(9)$, with equilibrium of the two concentrations being reached 5-6 min later], the TCI of Pro was initiated. When the patient lost consciousness [Observer's Assessment of Alertness/Sedation (OAA/S) scale score $\leq 2], 0.1 \mathrm{mg} / \mathrm{kg}$ vecuronium (batch no. 070704.1; Xianju Pharmaceutical Co., Ltd., Zhejiang, China) was intravenously injected. Then, connection to the intubation and anesthesia instrumentation was performed and the peak end tidal $\mathrm{CO}_{2}\left(\mathrm{PETCO}_{2}\right)$ level was maintained at $35-45 \mathrm{mmHg}$. After $3 \mathrm{~min}$, the HS2301 self-retaining laryngoscope (Shanghai Hengsheng Medical Instrument Co., Ltd., Shanghai, China) was inserted, and the surgery was conducted. If a reduction in HR or systolic BP occurred during the induction of anesthesia, cardiovascular drug treatment was applied until the patient's HR or blood pressure was stable (observed for $1 \mathrm{~min}$ ). The laryngoscopic surgery was then conducted, and the monitoring that was initiated prior to treatment was continued, and values were recorded. If the HR or mean arterial BP increased during laryngoscope insertion, the Rem target concentration was adjusted to a higher level for completion of the surgery (while the concentration for next patient was determined on the basis of the initial concentration). The Pro plasma concentration was controlled at $4 \mu \mathrm{g} / \mathrm{ml}$ (Marsh pharmacokinetic parameters) (10). The Rem target-controlled plasma concentration (Minto pharmacokinetic parameters) (11) was determined according to the $\mathrm{EC}_{50}$ sequential method, that is, the patient's plasma target-controlled concentration was determined by the previous patient's cardiovascular responses; if the previous patient exhibited SRLCCRs, the next higher concentration level was used; if there were no SRLCCRs, a lower-level concentration was applied. The ratio of two adjacent concentrations was 1.2. The test started from a Rem target-controlled plasma concentration of $5 \mathrm{ng} / \mathrm{ml}$, and the concentration for each case was calculated from the previous case on the basis of whether cardiovascular reactions were exhibited.

Observation items and scoring. The values of HR, mean (arterial) blood pressure (MBP) and the auditory evoked potential (AEP)-based A-line ARX Index (AAI) were recorded. The data acquisition time points were: Baseline value (T0), after anesthesia induction (T1), prior to laryngoscope insertion (T2) and highest value within $3 \mathrm{~min}$ after laryngoscope insertion (T3). Each value was recorded three times and averaged. Changes of HR, MBP and/or AAI of $>15 \%$ were considered as positive cardiovascular responses.

Sedation scoring was initiated after the Pro infusion, and the OAA/S scale score (12) was used to assess the patient's degree of sedation. The scores were recorded at T1, T2 and $\mathrm{T} 3$, respectively.

Arterial blood samples $(5 \mathrm{ml})$ were drawn at T2 and T3 for the measurement of stress indicators, namely cortisol and the inflammatory marker interleukin (IL)-6 using radioimmunoassay kits (Fuzhou Maixin Biotechnology Development Co., Ltd., Fuzhou, China). Blood glucose levels were measured using a type II blood glucose meter (Roche Diagnostics (Shanghai) Ltd., Shanghai, China) at T2 and T3.

Statistical analysis. The $\mathrm{EC}_{50}$ sequential method was used (13) to calculate the effective plasma concentration of Rem that inhibited SRLCCR in $50 \%$ of patients (the $\mathrm{EC}_{50}$ ). The valid number (r) and invalid number (s) of SRLCCR inhibitions under a specific Rem plasma target concentration were analyzed, and the logarithm of each plasma target concentration (x), the total number of patients (n), efficiency (p) of SRLCCR inhibition, and difference (d) of logarithms of two adjacent concentrations were determined and used to calculate the $\mathrm{EC}_{50}$ and $95 \%$ confidence interval (CI) by the $\mathrm{EC}_{50}$ sequential method. The following formulae were used: Logarithm of $\mathrm{EC}_{50}\left(\lg \mathrm{EC}_{50}\right)=\sum \mathrm{nx} / \sum \mathrm{n}$; standard deviation

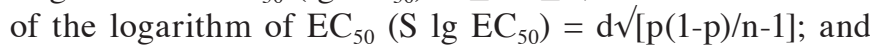
$95 \% \mathrm{CI}$ for the overall $\mathrm{EC}_{50}=\left(\lg \mathrm{EC}_{50}-1.96 \mathrm{~S} \mathrm{lg} \mathrm{EC}_{50}\right.$ to

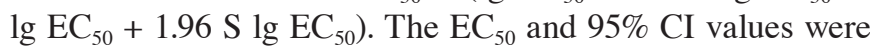
reported as the anti-logarithm of each logarithmic number. The average values of cortisol, IL-6 and glucose under the Rem plasma target-controlled concentration were determined, and intragroup comparisons were conducted using paired t-tests. Measurement data are expressed as mean \pm standard deviation. SPSS software, version 11.5 (SPSS, Inc., Chicago, IL, USA) was used for statistical processing, with $\mathrm{P}<0.05$ considered to indicate a statistically significant difference. 
Table I. General information of the patients in the five groups.

\begin{tabular}{lccccc}
\hline Variable & Group A & Group B & Group C & Group D & Group E \\
\hline Age (years) & 38 & $39.6 \pm 7.9$ & $42.2 \pm 6.8$ & $36.3 \pm 5.9$ & 44 \\
Gender (male/female) & $2 / 0$ & $4 / 2$ & $3 / 3$ & $69.6 \pm 9.4$ & $65.6 \pm 10.6$
\end{tabular}

Target remifentanil concentration: Group A, 5 ng/ml; group B, 4.2 ng/ml; group C, 3.5 ng/ml; group D, 2.9 ng/ml; group E, 2.4 ng/ml.

Table II. Remifentanil plasma target-controlled concentration.

\begin{tabular}{|c|c|c|c|c|c|}
\hline $\begin{array}{l}\text { Plasma } \\
\text { target-controlled } \\
\text { concentration } \\
(\mathrm{ng} / \mathrm{ml})\end{array}$ & $\begin{array}{c}\text { Log plasma } \\
\text { target-controlled } \\
\text { concentration }(\mathrm{x})\end{array}$ & $\begin{array}{l}\text { Total cases for } \\
\text { each plasma } \\
\text { target-controlled } \\
\text { concentration (n) }\end{array}$ & $\begin{array}{c}\text { Valid } \\
\text { cases of } \\
\text { SRLCCR } \\
\text { inhibition (r) }\end{array}$ & $\begin{array}{c}\text { Invalid } \\
\text { cases of } \\
\text { SRLCCR } \\
\text { inhibition (s) }\end{array}$ & $\begin{array}{c}\text { Valid } \\
\text { rate }(\%) \text { of } \\
\text { SRLCCR } \\
\text { inhibition }(\mathrm{p})\end{array}$ \\
\hline 5 & 0.699 & 2 & 2 & 0 & 100 \\
\hline 4.2 & 0.623 & 6 & 4 & 2 & 66.7 \\
\hline 3.5 & 0.544 & 6 & 3 & 3 & 50.0 \\
\hline 2.9 & 0.477 & 4 & 2 & 2 & 50.0 \\
\hline 2.4 & 0.398 & 2 & 0 & 2 & 0 \\
\hline
\end{tabular}

Difference of logarithms of two adjacent concentrations, $d=0.07918$. SRLCCR, self-retaining laryngoscope-caused cardiovascular response.

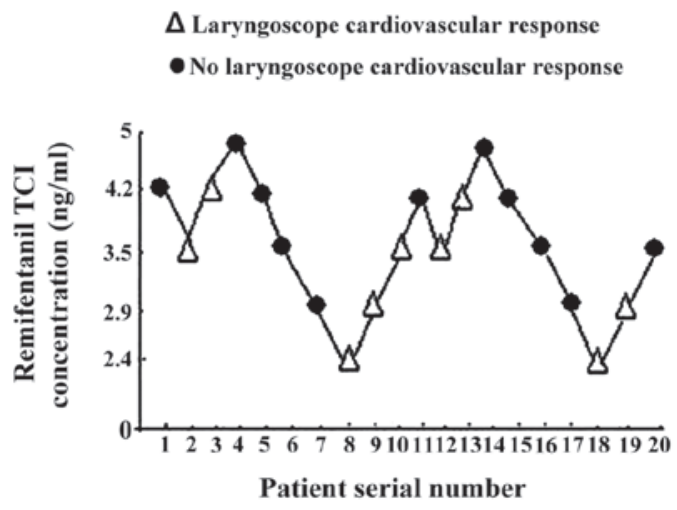

Figure 1. Curve of remifentanil plasma target-controlled concentration for SRLCCR inhibition. TCI, target-controlled infusion.

\section{Results}

General patient information and grouping. A total of 20 patients were enrolled in the present study The Rem target concentrations of the selected patients were set as follows: 2 cases at $5 \mathrm{ng}$ / $\mathrm{ml}, 6$ cases at $4.2 \mathrm{ng} / \mathrm{ml}, 6$ cases at $3.5 \mathrm{ng} / \mathrm{ml}, 4$ cases at $2.9 \mathrm{ng} / \mathrm{ml}$ and 2 cases at $2.4 \mathrm{ng} / \mathrm{ml}$. The 20 patients were then divided into five groups, for analysis according to the different target concentrations of Rem; Group A, $5 \mathrm{ng} / \mathrm{ml}$; group B, $4.2 \mathrm{ng} / \mathrm{ml}$; group C, $3.5 \mathrm{ng} / \mathrm{ml}$; group D, $2.9 \mathrm{ng} / \mathrm{ml}$; and group E, $2.4 \mathrm{ng} / \mathrm{ml}$. No statistically significant difference in age, weight and gender was observed among the five groups ( $\mathrm{P}>0.05$; Table I).

During testing, 1 patient was excluded due to the occurrence of laryngoscope-induced bradycardia (HR, <50 beats/min), but none of the patients exhibited any chest wall stiffness.
Postoperative questioning confirmed that no patients experienced intraoperative awareness.

Calculation of the $E C_{50}$. The valid number (r) and invalid number (s) of SRLCCR inhibitions under each Rem plasma target concentration were analyzed, and the logarithm of each plasma target concentration (x), total number of patients (n), efficiency (p) of SRLCCR inhibition and difference (d) of logarithms of two adjacent concentrations were calculated, and the results are presented in Table II. The $\mathrm{EC}_{50}$ value calculated according to the $\mathrm{EC}_{50}$ sequential method was $3.5 \mathrm{ng} / \mathrm{ml}$ and the 95\% CI was 3.47-3.60.

The Rem target-controlled plasma concentrations for SRLCCR inhibition in each patient are shown in Fig. 1.

Changes of $H R, M B P$ and AAI. With regard to HR, the $\mathrm{HR}$ at $\mathrm{T} 1$ was reduced compared with that at $\mathrm{T} 0$ in group $\mathrm{A}(\mathrm{P}<0.05)$ and group $\mathrm{B}(\mathrm{P}<0.01)$. In addition, the HRs at T3 were significantly increased compared with those at $\mathrm{T} 2$ in groups $\mathrm{D}$ and $\mathrm{E}$ $(\mathrm{P}<0.05$; Table III).

With regard to blood pressure, the MBP values for groups A and $\mathrm{D}$ at $\mathrm{T} 1$ were reduced compared with those at $\mathrm{T} 0(\mathrm{P}<0.05)$; the MBP values at $\mathrm{T} 1$ of groups $\mathrm{B}$ and $\mathrm{C}$ were also reduced compared with those at T0, with a higher level of significance $(\mathrm{P}<0.01)$. In groups $\mathrm{D}$ and $\mathrm{E}$, the MBP values at $\mathrm{T} 3$ were significantly increased compared with those at $\mathrm{T} 2$ ( $\mathrm{P}<0.05$; Table III).

The AAI value at $\mathrm{T} 1$ was reduced compared with that at $\mathrm{T} 0$ in group $\mathrm{A}(\mathrm{P}<0.05)$. In groups $\mathrm{B}, \mathrm{C}$ and $\mathrm{D}$, the $\mathrm{AAI}$ values at $\mathrm{T} 1$ were also reduced compared with those at $\mathrm{T} 0$, with a higher level of significance $(\mathrm{P}<0.01)$. Furthermore, the AAI values in groups D and E at T3 were significantly increased compared with those at $\mathrm{T} 2(\mathrm{P}<0.05$; Table III). 
Table III. HR, MBP and AAI changes of the five groups at different time points (mean \pm standard deviation).

\begin{tabular}{|c|c|c|c|c|c|c|}
\hline Indices & Time point & Group A & Group B & Group C & Group D & Group E \\
\hline \multirow[t]{4}{*}{ HR (bpm) } & T0 & $98.0 \pm 1.4$ & $88.3 \pm 2.8$ & $74.2 \pm 6.6$ & $79.2 \pm 6.6$ & $76.5 \pm 4.3$ \\
\hline & $\mathrm{T} 1$ & $68.4 \pm 2.3^{\mathrm{a}}$ & $76.5 \pm 6.7^{b}$ & $69.7 \pm 3.3$ & $78.9 \pm 5.8$ & $75.3 \pm 2.8$ \\
\hline & $\mathrm{T} 2$ & $74.0 \pm 4.6$ & $77.0 \pm 5.6$ & $72.1 \pm 3.6$ & $81.0 \pm 5.4$ & $80.3 \pm 4.7$ \\
\hline & $\mathrm{T} 3$ & $75.3 \pm 5.5$ & $80.8 \pm 6.2$ & $78.8 \pm 5.4$ & $89.0 \pm 2.6^{c}$ & $113.5 \pm 8.3^{c}$ \\
\hline \multirow[t]{4}{*}{$\mathrm{MBP}(\mathrm{mmHg})$} & T0 & $102.1 \pm 7.6$ & $100.5 \pm 5.6$ & $99.4 \pm 4.9$ & $95.7 \pm 5.2$ & $94.1 \pm 2.3$ \\
\hline & $\mathrm{T} 1$ & $83.3 \pm 5.7^{\mathrm{a}}$ & $83.8 \pm 4.1^{\mathrm{b}}$ & $83.5 \pm 3.8^{b}$ & $86.3 \pm 6.6^{\mathrm{a}}$ & $90.5 \pm 1.2$ \\
\hline & $\mathrm{T} 2$ & $86.8 \pm 3.5$ & $87.0 \pm 3.6$ & $86.0 \pm 3.0$ & $88.2 \pm 6.4$ & $94.6 \pm 3.2$ \\
\hline & $\mathrm{T} 3$ & $91.0 \pm 4.4$ & $93.0 \pm 6.3$ & $94.3 \pm 6.3$ & $100.1 \pm 11.4^{c}$ & $123.9 \pm 5.2^{\mathrm{c}}$ \\
\hline \multirow[t]{4}{*}{ AAI } & T0 & $70.3 \pm 2.1$ & $75.3 \pm 6.1$ & $76.3 \pm 4.4$ & $69.9 \pm 5.9$ & $72.4 \pm 9.5$ \\
\hline & $\mathrm{T} 1$ & $19.9 \pm 4.7^{\mathrm{a}}$ & $21.1 \pm 2.5^{\mathrm{b}}$ & $20.6 \pm 3.2^{b}$ & $20.8 \pm 7.0^{\mathrm{b}}$ & $24.7 \pm 2.8$ \\
\hline & $\mathrm{T} 2$ & $21.9 \pm 3.8$ & $21.9 \pm 2.0$ & $20.6 \pm 2.4$ & $25.8 \pm 3.4$ & $26.0 \pm 5.9$ \\
\hline & $\mathrm{T} 3$ & $21.3 \pm 4.9$ & $22.6 \pm 2.3$ & $23.3 \pm 3.0$ & $30.2 \pm 2.7^{\mathrm{c}}$ & $40.2 \pm 6.4^{\mathrm{c}}$ \\
\hline
\end{tabular}

HR, heart rate; MBP, mean blood pressure; AAI, A-line ARX Index; Group A, target remifentanil concentration 5 ng/ml; group B, target remifentanil concentration $4.2 \mathrm{ng} / \mathrm{ml}$; group C, target remifentanil concentration $3.5 \mathrm{ng} / \mathrm{ml}$; group D, target remifentanil concentration $2.9 \mathrm{ng} / \mathrm{ml}$; group E, target remifentanil concentration $2.4 \mathrm{ng} / \mathrm{ml}$; T0, baseline; T1, after induction of anesthesia; T2, before laryngoscope insertion; T3, after laryngoscope insertion. ${ }^{\mathrm{a}} \mathrm{P}<0.05,{ }^{\mathrm{b}} \mathrm{P}<0.01 \mathrm{vs}$. $\mathrm{T} 0 ;{ }^{\mathrm{c}} \mathrm{P}<0.05$ vs. $\mathrm{T} 2$.

Table IV. Cortisol, IL-6 and blood glucose levels in the five groups at different time points (mean \pm standard deviation).

\begin{tabular}{lcccccc}
\hline Indices & Time point & Group A & Group B & Group C & Group D & Group E \\
\hline Cortisol $(\mathrm{ng} / \mathrm{ml})$ & T2 & $180.60 \pm 23.76$ & $176.73 \pm 13.24$ & $180.45 \pm 13.23$ & $184.65 \pm 5.85$ & $186.45 \pm 10.25$ \\
& T3 & $181.05 \pm 12.23$ & $185.78 \pm 11.37$ & $188.17 \pm 7.66$ & $239.80 \pm 24.94^{\mathrm{a}}$ & $282.05 \pm 16.33^{\mathrm{a}}$ \\
& T2 & $0.71 \pm 0.06$ & $0.72 \pm 0.06$ & $0.73 \pm 0.07$ & $0.86 \pm 0.05$ & $0.87 \pm 0.06$ \\
IL-6 (ng/ml) & T3 & $0.74 \pm 0.08$ & $0.78 \pm 0.06$ & $0.79 \pm 0.08$ & $0.95 \pm 0.07^{\mathrm{a}}$ & $1.62 \pm 0.18$ \\
Blood glucose (mmol/1) & T2 & $4.90 \pm 0.28$ & $4.68 \pm 0.84$ & $4.97 \pm 0.60$ & $4.98 \pm 0.85$ & $5.55 \pm 0.21$ \\
& T3 & $5.00 \pm 0.57$ & $4.80 \pm 0.73$ & $5.20 \pm 0.39$ & $5.78 \pm 0.50^{\mathrm{a}}$ & $7.70 \pm 0.42^{\mathrm{a}}$ \\
\hline
\end{tabular}

IL, interleukin; Group A, target remifentanil concentration $5 \mathrm{ng} / \mathrm{ml}$; group B, target remifentanil concentration $4.2 \mathrm{ng} / \mathrm{ml}$; group C, target remifentanil concentration $3.5 \mathrm{ng} / \mathrm{ml}$; group D, target remifentanil concentration $2.9 \mathrm{ng} / \mathrm{ml}$; group E, target remifentanil concentration $2.4 \mathrm{ng} / \mathrm{ml}$; $\mathrm{T} 2$, before laryngoscope insertion; T3, after laryngoscope insertion. ${ }^{\mathrm{a}} \mathrm{P}<0.05 \mathrm{vs}$. T2.

Changes of cortisol, IL-6 and blood sugar levels. When stress indicators were examined, it was observed that the cortisol levels and blood sugar levels at T3 of groups D and E were increased compared with those at $\mathrm{T} 2$, and the differences were statistically significant $(\mathrm{P}<0.05$; Table IV). In addition, in group D, the IL-6 level at T3 was increased compared with that at $\mathrm{T} 2(\mathrm{P}<0.05$; Table IV $)$.

$O A A / S$ scores. All patients exhibited no response towards the deltoid extrusion pushing examination conducted at T1, T2 and T3, and thus had a corresponding OAA/S score of 1 . No significant differences were observed.

\section{Discussion}

Vocal cord surgery using a self-retaining laryngoscope involves a short operation with a strong stimulus; although the duration of surgery is short, the requirements of anesthesia are high, as it should not only reduce stress responses and the throat reflex and fully relax the muscles, but also enable the patient to recover and rehabilitate from the surgery as soon as possible (2). Thus, the timely mastering of the depth of anesthesia is very important, and the scientific and rational determination of drug dosage during the anesthesia is essential. The present study was conducted to determine the drug dosage for Rem, and the results are analyzed as follows.

Cortisol has been demonstrated to be a stress indicator; for example, Haussmann et al studied healthy human volunteers under three different stressful conditions, and found that the salivary cortisol levels were significantly increased following each type of stress (14). The present study showed that the plasma cortisol values groups A, B and C at T3 were higher than those at $\mathrm{T} 2$, but the difference was not significant ( $P>0.05)$. However, it could be considered that the intubation affected cortisol production, as the plasma cortisol levels of groups D and E group increased significantly at T3 compared with T2 $(\mathrm{P}<0.05)$. These results indicate that when Rem was 
$\leq 2.9 \mathrm{ng} / \mathrm{ml}$, it could not effectively inhibit the stress responses caused by the laryngoscope.

IL-6 is an important type of inflammatory cytokine that can mediate the pathophysiological process of stress; the stimulus of surgical trauma could potentially induce the excessive production of IL-6. It is considered that IL-6 is a particularly sensitive inflammatory marker that can reflect tissue damage and the degree of stress $(15,16)$. A prior study suggested that changes of IL- 6 levels occur earlier and are more sensitive than those of cortisol (17). In the present study, the IL- 6 values of all groups at T3 were higher than those at T2. However, while the changes in groups A, B, C and E were not significant $(\mathrm{P}>0.05)$, the plasma IL-6 level of group D was significantly increased following insertion of the laryngoscope $(\mathrm{P}<0.05)$. These results indicate that when the Rem concentration was $2.9 \mathrm{ng} / \mathrm{ml}$, it could not inhibit laryngoscope-induced IL-6 induction. The IL-6 levels of group E changed notably between T2 and T3, although not in a statistically significant manner, which might be due to the small number of patients in this group.

A previous study has confirmed that glucose is an effective indicator that can reflect the stress response (18). Testing has shown that following laparoscopic surgery, blood glucose and cortisol values showed significant differences from those preoperatively (19). The present study showed that there was no significant change in the blood glucose values of groups A, B and $\mathrm{C}$ before and after laryngoscope insertion $(\mathrm{P}>0.05)$, while those of groups D and E at T3 were significantly increased compared with those at $\mathrm{T} 2(\mathrm{P}<0.05)$, indicating that when the Rem dosage was $<2.9 \mathrm{ng} / \mathrm{ml}$, it could not effectively suppress the high metabolic changes caused by laryngoscope insertion.

The results showed that $\mathrm{HR}$ at $\mathrm{T} 1$ was lower than that at $\mathrm{T} 0$ for group $\mathrm{A}(\mathrm{P}<0.05)$ and group $\mathrm{B}(\mathrm{P}<0.01)$, and the HRs of groups $\mathrm{D}$ and $\mathrm{E}$ at $\mathrm{T} 3$ were significantly increased compared with those at $\mathrm{T} 2(\mathrm{P}<0.05)$. One patient received emergency treatment due to the rapid $\mathrm{HR}$ reduction during insertion of the laryngoscope ( $<50$ beats/min), and thus was excluded. One patient of group A exhibited a decreased HR following the induction of anesthesia, and thus required atropine treatment; 2 cases from groups D and E, respectively, had an increased Rem target-controlled concentration for the increased HR following laryngoscope insertion. This result indicated that when the Rem plasma target-controlled concentrations were 4.2 and $5 \mathrm{ng} / \mathrm{ml}$, the patients might exhibit induced cardiovascular responses, while at these concentrations, it would be difficult to achieve effective inhibition of laryngoscope-induced changes in HR. This result is essentially consistent with the $\mathrm{EC}_{50}$, calculated by the $\mathrm{EC}_{50}$ sequential method, and the above analysis.

Rem can expand the arteries to various degrees (20), and excessive medication could cause the lowering of blood pressure. The results of the present study showed that the patients of each group exhibited a reduction in MBP at T1 compared with that at $\mathrm{T} 0$, which might be considered to be associated with the blood pressure-lowering effects of Pro. However, the reduction of group $\mathrm{E}$ was not significant $(\mathrm{P}>0.05)$, whereas the reductions at $\mathrm{T} 1$ compared with those at $\mathrm{T} 0$ were significant for groups $\mathrm{A}$ and $\mathrm{D}(\mathrm{P}<0.05)$ and groups $\mathrm{B}$ and $\mathrm{C}(\mathrm{P}<0.01)$. The MBPs of groups D and E at T3 were significantly increased compared with those at $\mathrm{T} 2(\mathrm{P}<0.05)$, among which 1 case of groups $\mathrm{A}, \mathrm{B}$ and $\mathrm{C}$, respectively, received ephedrine treatment because of blood pressure reduction at $\mathrm{T} 1$, and 1 case of group D and 2 cases of group E underwent adjustment of the Rem target concentration at T3 due to the increase in blood pressure. These results indicate that when the Rem target concentrations were 2.9 and $2.4 \mathrm{ng} / \mathrm{ml}$ it was difficult to effectively suppress the elevated blood pressure caused by the insertion of the laryngoscope. This result is essentially consistent with the above analysis. Whether Rem and Pro had a synergistic effect in lowering the blood pressure requires further investigation.

AAI is the AEP index derived from the usage of an A-line monitoring instrument; AEP can accurately reflect the situations of sedation and analgesia, as well as the prediction of short-term body movements (21). AAI values are normally in the range 0-100. Generally, it is considered that AAI 60-100 represents the normal waking state, 40-60 represents the sleep state, 30-40 represents the light anesthesia state, $<30$ represents the clinical anesthesia state and $<10$ represents the deep anesthesia state (22). It has been suggested that AAI can much more sensitively reflect the depth of anesthesia than the bispectral index in Pro-fentanyl anesthesia (23). The present study showed that the AAI of group A at T1 was decreased compared with that at T0 $(\mathrm{P}<0.05)$, and those of groups $\mathrm{B}, \mathrm{C}$ and $\mathrm{D}$ at $\mathrm{T} 1$ were significantly lower than those at T0 $(\mathrm{P}<0.01)$; those of groups D and E at T3 were significantly increased compared with those at T2 $(\mathrm{P}<0.05)$. Kreuer et al (24) studied the AAI changes during anesthesia with Pro and Rem, and hypothesized that in Pro and Rem anesthesia, a large variation in the AAI values might exist when the patient is awake, which might explain the reduction of AAI values of groups $\mathrm{A}, \mathrm{B}$ and $\mathrm{C}$ after the induction of anesthesia.

In this study, sedation/alert scoring was performed from the initiation of Pro TCI, and the results showed that the $\mathrm{OAA} / \mathrm{S}$ scores at three time points of all the patients were 1 , indicating that the patients were in the deep sleep state.

$\mathrm{EC}_{50}$ is a new concept for target-controlled intravenous infusion drugs, with its meaning equivalent to the minimum effective concentration of alveolar gas in inhalation anesthesia. In this study, the $\mathrm{EC}_{50}$ sequential method was used to calculate the $\mathrm{EC}_{50}$ of Rem-inhibited SRLCCR, so the patient selection was conducted in accordance with the requirements of the $\mathrm{EC}_{50}$ sequential method, with a total number of between 12 and 20.

It was calculated that the $\mathrm{EC}_{50}$ of Rem for the inhibition of SRLCCRs was $3.5 \mathrm{ng} / \mathrm{ml}$, with a $95 \% \mathrm{CI}$ of $3.47-3.60 \mathrm{ng} / \mathrm{ml}$. This study suggested that when the Pro target-controlled concentration was $4 \mu \mathrm{g} / \mathrm{ml}$ and the concentration of Rem was 5 or $4.2 \mathrm{ng} / \mathrm{ml}$ obvious inhibition of the cardiovascular system could be achieved; while Rem target concentrations of 2.9 and $2.4 \mathrm{ng} / \mathrm{ml}$ may be insufficient to effectively inhibit SRLCCRs. When all patients were anesthetized, the OAA/S scores prior to and following laryngoscope insertion were 1, indicating that the patients were in the deep sleep state. From the above analysis, it could be concluded that a Pro concentration of $4 \mu \mathrm{g} / \mathrm{ml}$ could maintain adequate sedation, and the increase of $\mathrm{HR}, \mathrm{MBP}$ and AAI in certain patients before the insertion was associated with the Rem dose.

In conclusion, the $\mathrm{EC}_{50}$ sequential method was used to calculate the $\mathrm{EC}_{50}(3.5 \mathrm{ng} / \mathrm{ml})$ and $95 \% \mathrm{CI}(3.47-3.60 \mathrm{ng} / \mathrm{ml})$ 
of Rem towards SRLCCR inhibition. The test results showed that a Pro concentration of $4 \mu \mathrm{g} / \mathrm{ml}$ could maintain adequate sedation. The dose of Rem that was able to effectively inhibit SRLCCRs while not causing a serious Rem-induced inhibition response was between 2.9 and $4.2 \mathrm{ng} / \mathrm{ml}$. This result is consistent with the results of calculation by the $\mathrm{EC}_{50}$ sequential method.

\section{References}

1. Ghause MS, Singh V, Kumar A, Wahal R, Bhatia VK and Agarwal J: A study of cardiovascular response during laryngoscopy and intubation and their attenuation by ultra short acting b-blocker esmolol. Indian J Anaesth 46: 104-106, 2002.

2. Yumoto E: Laryngeal surgery-vocal cord polyp and anaesthesia. Nihon Jibiinkoka Gakkai Kaiho 116: 34-37, 2013 (In Japanese).

3. Yoo HS, Han JH, Park SW and Kim KS: Comparison of surgical condition in endoscopic sinus surgery using remifentanil combined with propofol, sevoflurane, or desflurane. Korean J Anesthesiol 59: 377-382, 2010.

4. Egan TD: Remifentanil: An esterase-metabolized opioid. West J Med 166: 202, 1997

5. Myre K, Raeder J, Rostrup M, Buanes T and Stokland O: Catecholamine release during laparoscpic fundoplication with high and low doses of remifentanil. Acta Anaesthesiol Scand 47: 267-273, 2003

6. Wu J, Mahmoud M, Schmitt M, Hossain M and Kurth D: Comparison of propofol and dexmedetomedine techniques in children undergoing magnetic resonance imaging. Paediatr Anaesth 24: 813-818, 2014

7. Sieg A; bng-Study-Group, Beck S, Scholl SG, Heil FJ, Gotthardt DN, Stremmel W, Rex DK and Friedrich K: Safety analysis of endoscopist-directed propofol sedation: A prospective, national multicenter study of 24441 patients in German outpatient practices. J Gastroenterol Hepatol 29: 517-523, 2014.

8. Khan HA, Umar M, Tul-Bushra H, Nisar G, Bilal M and Umar S: Safety of non-anaesthesiologist-administered propofol sedation in ERCP. Arab J Gastroenterol 15: 32-35, 2014.

9. Minto CF, Schnider TW and Shafer SL: Pharmacokinetics and pharmacodynamics of remifentanil. II. Model application. Anesthesiology 86: 24-33, 1997.

10. Coetzee JF, Glen JB, Wium CA and Boshoff L: Pharmacokinetic model selection for target controlled infusions of propofol. Anesthesiol 82: 1328-1345, 1995.
11. Minto CF, Schnider TW and Shafer SL: Pharmacokinetics and pharmacodynamics of remifentanil. II. Model application. Anesthesiology 86: 24-33, 1997.

12. Chernik DA, Gillings D, Laine H, Hendler J, Silver JM, Davidson AB, Schwam EM and Siegel JL: Validity and reliability of the Observers Assessment of Alertness/Sedation scale: Study with intravenous midazolam. J Clin Psychopharmacol 10: 244-251, 1990.

13. Yang SQ (ed): China Medical Encyclopedia - Medical Statistics. 1st edition, Shanghai Science and Technology Press, Shanghai, pp203-204, 2011.

14. Haussmann MF, Vleck CM and Farrar ES: A laboratory exercise to illustrate increased salivary cortisol in response to three stressful conditions using competitive ELISA. Adv Physiol Educ 31: 110-115, 2007.

15. Okholm C, Goetze JP, Svendsen LB and Achiam MP: Inflammatory response in laparoscopic vs. open surgery for gastric cancer. Scand J Gastroenterol 49: 1027-1034, 2014.

16. Wang SZ, Chen Y,Lin HY and Chen LW: Comparison of surgical stress response to laparoscopic and open radical cystectomy. World J Urol 28: 451-455, 2010.

17. Kristiansson M, Saraste L, Soop M, Sundqvist KG and Thörne A: Diminished interleukin 6 and $C$ reactive protein response to laparoscopic versus open cholecystectomy. Acta Anesthesiol Scand 43: 146-152, 1999.

18. Kehlet H: Multimodel approach to control postoperative pathophysiology and rehabilitation. Br J Anaesth 78: 606-617, 1997.

19. Cooper GM,Scoggins AM, Ward ID and Murphy D: Laparoscopy - a stressful procedure. Anaesthesia 37: 266-269, 1982.

20. Unlügenç H, Itegin M, Ocal I, Ozalevli M, Güler T and Işik G: Remifentanil produces vasorelaxation in isolated rat thoracic aorta strips. Acta Anaesthesiol Scand 48: 797, 2004.

21. Doi M, Gajraj RJ, Mantzaridis H and Kenny GN: Prediction of movement at laryngeal mask airway insertion: Comparison of auditory evoked potential index, bispectral index, spectral edge frequency and median frequency. Br J Anaesth 82: 203-207, 1999.

22. Alpiger S, Helbo-Hansen HS, Vach W and Ording H: Efficacy of A-line AEP Monitor as a tool for predicting acceptable tracheal intubation conditions during sevoflurane anaesthesia. $\mathrm{Br}$ J Anaesth 94: 601-606, 2005.

23. Nishiyama T and Hanaoka K: The A-line ARX index may be a more sensitive detector of arousal than the bispectral index during propofol-fentanyl-nitrous oxide anesthesia: A preliminary investigation. Can J Anaesth 51: 539-544, 2004.

24. Kreuer S, Bruhn J, Larsen R, Hoepstein M and Wilhelm W: Comparison of Alaris AEP index and bispectral index during propofol-remifentanil anaesthesia. Br J Anaesth 91: 336-340, 2003. 